\title{
Reduced Combustion Mechanism for Fire with Light Alcohols
}

\author{
Fekadu Mosisa Wako, Gianmaria Pio*(D) and Ernesto Salzano (D) \\ Department of Civil, Chemical, Environmental and Materials Engineering, University of Bologna, \\ 40126 Bologna, Italy; fekadumosisa.wako2@unibo.it (F.M.W.); ernesto.salzano@unibo.it (E.S.) \\ * Correspondence: gianmaria.pio@unibo.it
}

check for

updates

Citation: Mosisa Wako, F.; Pio, G.;

Salzano, E. Reduced Combustion

Mechanism for Fire with Light

Alcohols. Fire 2021, 4, 86. https://

doi.org/10.3390/fire4040086

Academic Editor:

Wojciech Węgrzyński

Received: 25 October 2021

Accepted: 17 November 2021

Published: 19 November 2021

Publisher's Note: MDPI stays neutral with regard to jurisdictional claims in published maps and institutional affiliations.

Copyright: (C) 2021 by the authors Licensee MDPI, Basel, Switzerland. This article is an open access article distributed under the terms and conditions of the Creative Commons Attribution (CC BY) license (https:/ / creativecommons.org/licenses/by/ $4.0 /)$.

\begin{abstract}
The need for sustainable energy has incentivized the use of alternative fuels such as light alcohols. In this work, reduced chemistry mechanisms for the prediction of fires (pool fire, tank fire, and flash fire) for two primary alcohols—methanol and ethanol—were developed, aiming to integrate the detailed kinetic model into the computational fluid dynamics (CFD) model. The model accommodates either the pure reactants and products or other intermediates, including soot precursors $\left(\mathrm{C}_{2} \mathrm{H}_{2}, \mathrm{C}_{2} \mathrm{H}_{4}\right.$, and $\left.\mathrm{C}_{3} \mathrm{H}_{3}\right)$, which were identified via sensitivity and reaction path analyses. The developed reduced mechanism was adopted to predict the burning behavior in a 3D domain and for the estimation of the product distribution. The agreement between the experimental data from the literature and estimations resulting from the analysis performed in this work demonstrates the successful application of this method for the integration of kinetic mechanisms and CFD models, opening to an accurate evaluation of safety scenarios and allowing for the proper design of storage and transportation systems involving light alcohols.
\end{abstract}

Keywords: light alcohol; detailed kinetic mechanism; fire; mechanism reduction; computational fluid dynamics

\section{Highlights:}

- Reduction of detailed kinetic mechanisms for methanol and ethanol fires;

- Definition of most relevant intermediates and reaction paths in alcohol combustion;

- Comparison against measured laminar burning velocity;

- Implementation of reduced mechanisms in computational fluid dynamics.

\section{Introduction}

The widespread use of alternative and bio-derived fuels in recent decades has incentivized research on the chemistry of oxygenated fuels and light alcohols in particular, starting with methanol and ethanol [1,2]. In addition, the development of robust and accurate mechanisms predicting the chemistry of light alcohols has positive spillovers in several industrial fields $[3,4]$. To analyze adiabatic systems with an initial low temperature, a wide range of conditions should be included per the mechanisms of generation. In addition, even though safety has not been regarded as a potential obstacle to the sustainable development of biofuel, many methanol processing or transportation industries often reported having fire accidents, causing casualties and property loss [5,6]. Thus, understanding the fuel chemistry of pool fires still requires extensive research. Considering the complexity of the investigated scenarios, the chemical and physical aspects are typically investigated separately. Under this impulse, several studies dedicated to the development of detailed kinetic mechanisms and accurate submodels for computational fluid dynamics have been performed, as briefly described in the following dedicated paragraphs.

\subsection{Kinetic Mechanisms}

Typically, combustion mechanisms distinguish high-temperature to low-temperature behaviors. Indeed, the former condition is characterized by the presence of a pyrolysis 
path, leading to the formation of aromatics and soot precursors via an increase in the aliphatic chain and hydrogen addition reactions. Two distinct paths can be conducted toward high-temperature oxidation. Both follow the $\mathrm{CH}_{2} \mathrm{O} \rightarrow \mathrm{HCO} \rightarrow \mathrm{CO} \rightarrow \mathrm{CO}_{2}$ route as the final steps. However, in one case, $\mathrm{CH}_{2} \mathrm{O}$ is produced via an alcohol intermediate by a hydrogen abstraction reaction followed by double bond formation, whereas in the other case, the abstraction site is on the hydrocarbon side [7].

Low-temperature combustion is characterized by having oxygen molecules as the dominant abstracting agents producing the alkyl group and hydroperoxy radical $\left(\mathrm{HO}_{2}\right)[8]$. This phenomenon can be attributed to the reduced availability of small radicals derived from dissociation reactions. Indeed, this reaction class is favored by elevated internal energy and momentum and thus hindered by decreases in temperature. The produced alkyl radical may undergo further hydrogen abstraction by oxygen to form an additional hydroperoxy radical and alkene or attract an oxygen molecule and produce a peroxyalkyl radical (R-OO). The latter is considered to be a barrierless reaction [9], justifying its dominant role at low temperatures. As an example, the described mechanism promotes the production of $\mathrm{HO}_{2}$, which determines the reactivity and ignition of the system under the investigated conditions because of the production of the hydrogen atom $(\mathrm{H})$ and hydroxyl radical $(\mathrm{OH})$. Conversely, this mechanism leads to more stable compounds (e.g., alkenes), reducing the overall reactivity and thus generating the so-called negative temperature coefficient (NTC) behavior [10]. The occurrence of this pathway is mostly determined by the operative conditions and the length of the aliphatic chain, as demonstrated by the negligible impact of the concerted elimination of $\mathrm{HO}_{2}$ for alkyl radicals larger than C4 [11]. Once the initiation reactions have activated the initial reactants, the internal migration of hydrogen atoms forming hydroperoxyalkyl radical $(\mathrm{QOOH})$ dominates at a temperature lower than $600 \mathrm{~K}$, whereas the disproportionation forming a hydroperoxide $(\mathrm{ROOH})$ rules higher temperatures [9]. The latter conditions promote decomposition in RO and $\mathrm{OH}$. Conversely, $\mathrm{QOOH}$ can produce peroxyhydroperoxyalkyl radicals $(\mathrm{OOQOOH})$ via oxygen's addition or decompose to cyclic ethers or acyclic species [12]. A simplified representation of the described mechanisms is provided for a generic organic species $\mathrm{RH}$ (Figure 1).

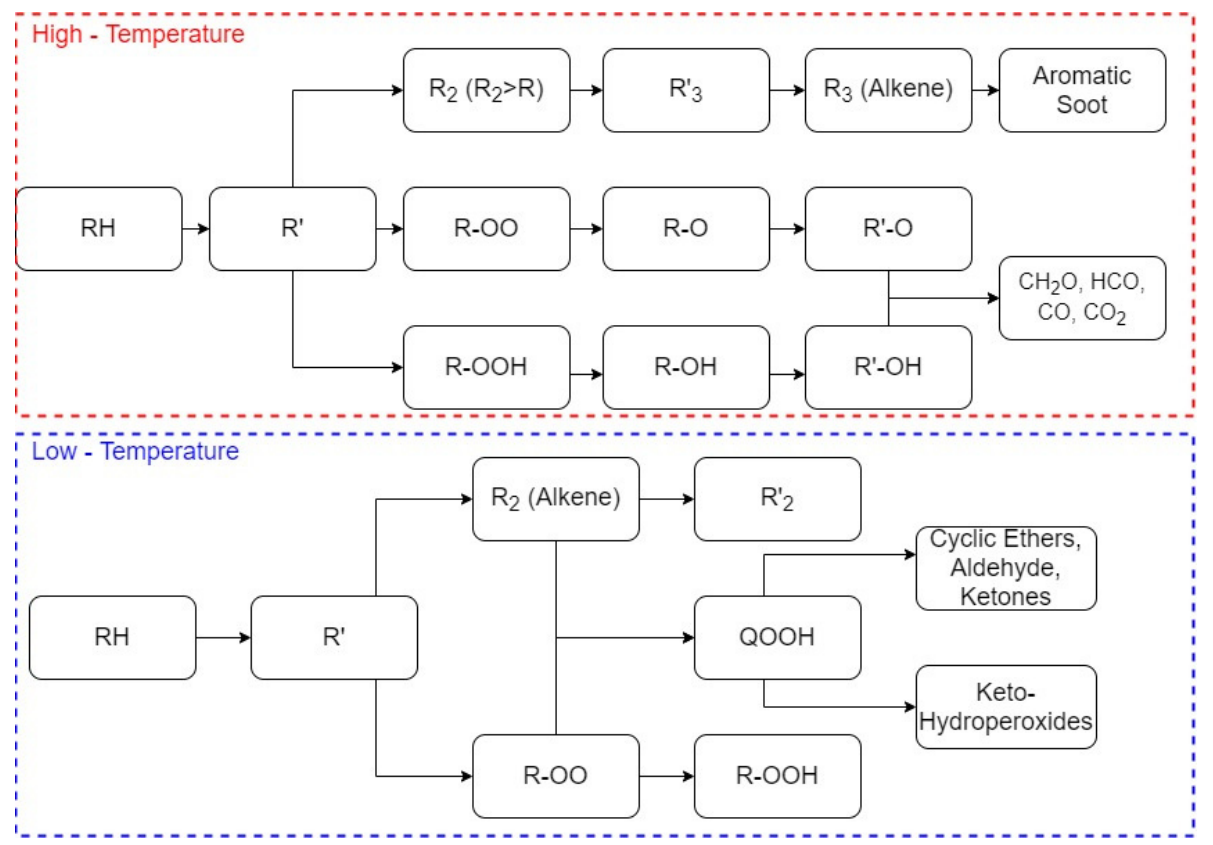

Figure 1. Simplified representation of the ruling kinetic mechanisms at high (top) and low (bottom) temperatures. 
The presence of a large number of alternatives for mechanism generation and techniques for the estimation of the required properties have jointly challenged the development of kinetic models [13], resulting in a large variety of sub-mechanisms [14,15] and potentially large uncertainty [16]. For a given carbon chain length, oxygenated substances have many potential fuel radical structures, which increases the number of reaction paths. In this regard, by determining the reactions dominating the overall reaction rates, many methods have been established to further simplify them [17]. Among them, sensitivity analysis is a well-established approach widely in use to evaluate the relevance of the reactions to the overall reactivity determined by kinetic models [18].

\subsection{Computational Fluid Dynamics}

The integration of kinetic mechanisms in computational fluid dynamics (CFD) models has been largely indicated as a straightforward strategy toward the optimization of processes and technological systems [19]. Considering the numerical nature of this approach, a comparison with experimental data is preferable for the sake of validation, as successfully implemented for the characterization of pool fires resulting from the accidental release of traditional fuels [20]. Indeed, a robust dataset of experimental data describing pool fires can be found for several liquid fuels and conditions. The cited outcomes have demonstrated the potentiality of this strategy for the integration of safety analysis, promoting similar studies for alternative fuels as well. In this perspective, it is worth saying that Weckman and Strong [21] studied the structures of medium-sized methanol pool fires and provided several measurement methods. The authors interpreted the large temperature and velocity change curves in the flowing fire field by measuring in and around the flame zone, thereby explaining the complex fluid dynamics and thermal interactions that control the fire's behavior. Recently, Falkenstein-Smith et al. (2021) [22] studied the chemical structures of medium-scale pool fires of methanol, ethanol, and acetone. In that study, time-averaged local temperatures and gas concentrations were measured to describe the chemical structures of the fuels in a $30-\mathrm{cm}$ diameter pool fire within a quiescent environment. In medium and large pool fires, radiant heat transfer was reported to be the main mechanism for feeding back heat to the fuel surface, where the concentration and temperatures of the species controlled the radiative heat transfer [22]. Vali et al. (2013) [23] studied the transport phenomena characterizing the burning rate of a methanol pool fire under steady state quiescent environmental conditions and the different temperatures of the substrate. Moreover, Fischer et al. [24] studied the effect of the pool's diameter on the flame structure in terms of temperature distribution and the mean average concentration of $\mathrm{CO}_{2}, \mathrm{CO}, \mathrm{H}_{2} \mathrm{O}$, and other hydrocarbons.

Concerning the numerical aspects, several licensed, academic, and open-source CFD may be adopted for detailed fire simulation of the flame, heat radiation, soot formation, and combustion product composition. Fire Dynamics Simulator (FDS) [25] is attracting attention and increasing the use of fire simulation software due to its efficiency, simplicity, and required computational power. Wen et al. (2007) [26] reproduced a medium-size methanol pool fire by using FDS, revealing a good ability to predict some key parameters such as the average temperature, velocity distribution, and air induction ratio. The structures and energy of the fire considering the gas-liquid phases of the fuel were studied by Prasad et al. [27] for the pool fire of methanol, showing a good agreement between the temperature and combustion rate. All the analyses reported above adopted a built-in, oversimplified kinetic model which did not allow for the detailed simulation of fire or the evaluation of the product distribution. Hence, the current work presents a first section devoted to the reduction of detailed kinetic mechanisms to guarantee stable numerical analyses and reduce the computational costs, followed by its implementation in the CFD model for the prediction of the pool fire parameters of methanol and ethanol. Aside from that, mechanism reduction helps to identify the key chemical species and reactions as well as the negligible paths and intermediates under the investigated conditions. 


\section{Methodology}

In this study, the individuation of the most relevant intermediate species and products along the combustion process of methanol and ethanol fuels was performed by using the CHEMKIN [28] preprocessor via sensitivity and reaction path analyses. More specifically, the reaction path analysis was devoted to the individuation of the most relevant intermediates, whereas the sensitivity analysis was committed to the individuation of the most influential reactions involved during the formation of these compounds. The pressure and equivalence ratio $(\varphi)$ (Equation (1)) in the reactor were set to a constant value of $1 \mathrm{~atm}$ and 1.0 , respectively, whereas a constant value within the range of $310-1400 \mathrm{~K}$ was attributed to the temperature in each simulation:

$$
\varphi=\sum \frac{\left(\frac{m_{f}}{m_{o x}}\right)}{\left(\frac{m_{f}}{m_{o x}}\right)_{s t}}
$$

where $\mathrm{m}$ is a mole fraction and $\mathrm{f}$ and ox are the fuel and oxidants, respectively. A stoichiometric mixture was considered as representative for the whole spectra of possible compositions, since the consideration of a wide range of initial temperatures guaranteed the inclusion of the most relevant ignition and extinction phenomena [29]. For this purpose, the detailed kinetic mechanism focused on butanol oxidation, developed by Sarathy et al. [30], was considered as representative of the chemistry of the light alcohol and used in this work. A perturbation of the input parameter (i.e., the kinetic coefficient of the ith equation $\mathrm{K}_{\mathrm{i}}$ ) was imposed on the system, and its effect on the laminar burning velocity $\left(\mathrm{S}_{\mathrm{u}}\right)$ was assessed. The results were presented in the form of normalized sensitivity coefficients (NSCs) as defined in Equation (2):

$$
\mathrm{NSC}=\left(\frac{\mathrm{K}_{\mathrm{i}}}{\mathrm{S}_{\mathrm{u}}}\right) \cdot \frac{\partial \mathrm{S}_{\mathrm{u}}}{\partial \mathrm{K}_{\mathrm{i}}}
$$

The laminar burning velocity is generally considered an independent parameter that characterizes the chemistry in an oxidative environment [31,32] and can help to further verify the accuracy of the kinetic mechanisms. To this aim, the numerical simulations of the laminar burning velocity were performed using a one-dimensional, freely propagating adiabatic flame via the Cantera [33] chemical solver. Further information on the adopted methodology can be found in previous work available in the current literature [34].

An accurate representation of the production and consumption of the intermediates and products needs to be determined for a better understanding of the flame dynamics and pollutant formation. Considering this, reaction path analysis (RPA) was used to identify the main relevant intermediate species in the reaction path and eliminate any species with negligible contributions, thereby verifying the species list. The relative size of the connection pathway is related to the relative contribution of the pathway to the species net yield [35]. That aside, other parameters such as the absolute and relative tolerances for the steady state problem were considered. The absolute and relative tolerance values implemented in this study were $1.0 \times 10^{-9}$ and $1.0 \times 10^{-4}$, respectively. Once the key relevant intermediates and products were identified, the reactions leading to the consumption and production of these species were collected from the detailed kinetic mechanism considered in the present study and sorted by decreasing absolute values of the normalized sensitivity coefficients. Reactions showing $|\mathrm{NSC}|>1$ were incorporated into the reduced kinetic mechanism.

As cited above, Fire Dynamic Simulator (FDS v5.5.3), an open-source code developed by the National Institute of Standards and Technology (NIST), was used to perform the fire simulation. Accordingly, the large eddy simulator (LES) model was adopted to numerically solve the Navier-Stokes equations relevant to low-speed thermally driven flows, focusing on the smoke and heat generated by fires as described in detail in the literature [36]. Then, the reduced mechanisms obtained in the present work were implemented into FDS for the evaluation of the pool fire scenarios, guaranteeing the inclusion of detailed chemistry 
in CFD. Indeed, the size of the original version of the adopted kinetic mechanism did not allow for its use in CFD because of the required computational power. The obtained estimations were compared with the so-called single-step reaction approach, included in the database of FDS (referred to as single-step chemistry from now on) and the experimental data retrieved from the current literature $[36,37]$. These experimental works were chosen for the sake of validation due to the convenience of the boundary conditions (e.g., the similar and small diameter of the pan) and the similarity of the measured properties (e.g., the temperature distribution and mass burning rate). The main boundary conditions were selected under the experimental conditions reported in the literature (Table 1) [36,37].

Table 1. The main boundary conditions implemented in this work, selected to mimic experimental data retrieved in the literature [36,37].

\begin{tabular}{ccccc}
\hline Fuel & Substrate & Pan Diameter $(\mathbf{m})$ & Initial Temperature (K) & Wind Speed $(\mathbf{m} / \mathbf{s})$ \\
\hline Methanol & Steel burner & 1.0 & 293 & 0 \\
Ethanol & Stainless steel & 1.0 & 328 & $3-4$ \\
\hline
\end{tabular}

\section{Results and Discussion}

The reaction path analysis conducted at a stoichiometric composition, atmospheric pressure, and temperature of $310 \mathrm{~K}$ are shown below in Figure 2 (methanol).

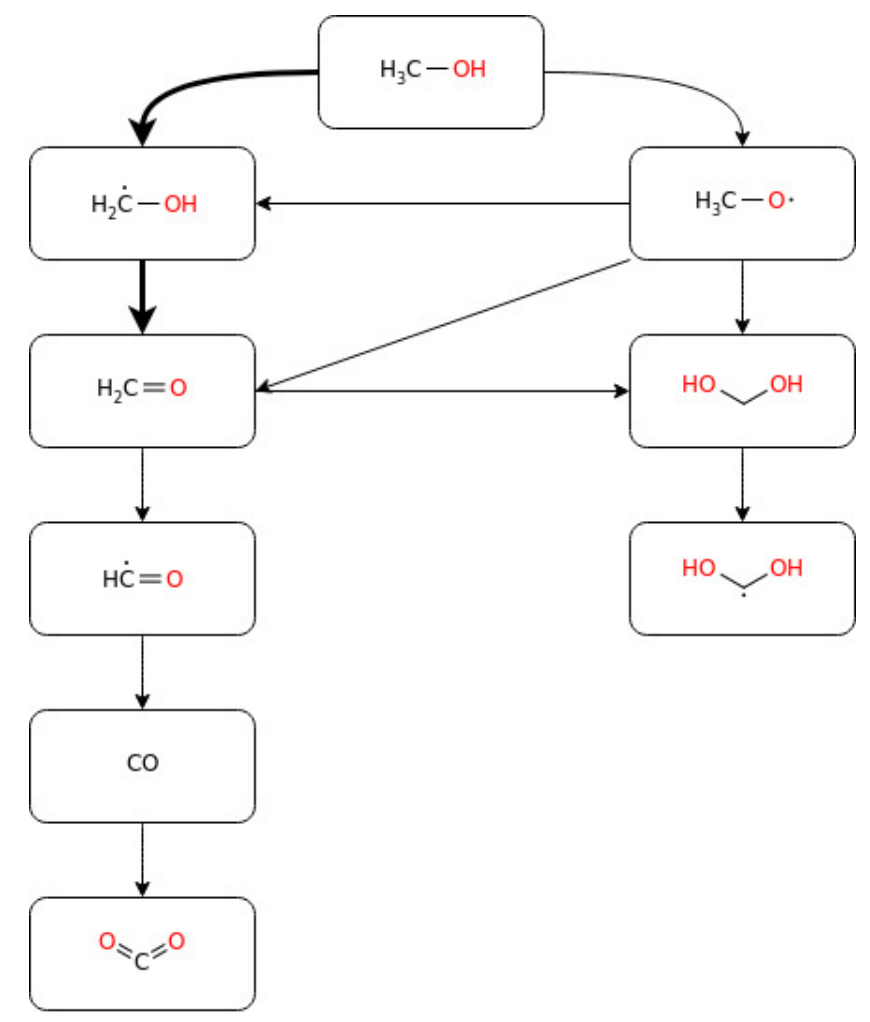

Figure 2. Simplified representation of the reaction paths of methanol in air.

It can be seen from Figure 2 that $\mathrm{CH}_{2} \mathrm{OH}$ was revealed as the dominating intermediate product produced by the primary reaction of $\mathrm{CH}_{3} \mathrm{OH}$. Aside from that, the contemporary formation of $\mathrm{HO}_{2}$ suggests that the hydrogen abstraction by $\mathrm{O}_{2}$ (i.e., $\mathrm{CH}_{3} \mathrm{OH}+\mathrm{O}_{2} \leftrightarrow$ $\mathrm{CH}_{2} \mathrm{OH}+\mathrm{HO}_{2}$ ) dominated the activation phase under the investigated conditions. Similarly, the consumption of $\mathrm{HCO}$ was mainly attributed to the formation of $\mathrm{CO}$ and $\mathrm{HO}_{2}$, indicating the crucial role of the hydrogen abstraction $\mathrm{HCO}+\mathrm{O}_{2} \leftrightarrow \mathrm{CO}+\mathrm{HO}_{2}$. The main decomposition path of methanol continued with the hydrogen abstraction from $\mathrm{CH}_{2} \mathrm{OH}$ concerted with a double bond formation, resulting in $\mathrm{CH}_{2} \mathrm{O}$. Additionally, through hydro- 
gen abstraction by $\mathrm{OH}, \mathrm{CH}_{3} \mathrm{OH}$ decomposed to $\mathrm{CH}_{3} \mathrm{O}$ (i.e., $\mathrm{CH}_{3} \mathrm{OH}+\mathrm{OH} \leftrightarrow \mathrm{CH}_{3} \mathrm{O}+\mathrm{H}_{2} \mathrm{O}$ ). $\mathrm{CH}_{3} \mathrm{O}$ further decomposed to produce $\mathrm{CH}_{2} \mathrm{OH}, \mathrm{CH}_{2} \mathrm{O}, \mathrm{HCO}$, and $\mathrm{HO}_{2}$. Aside from that, $\mathrm{CH}_{2} \mathrm{OH}$ produced $\mathrm{HOCH}_{2} \mathrm{O}$ through hydrogen abstraction by $\mathrm{HO}_{2}\left(\mathrm{CH}_{2} \mathrm{OH}+\mathrm{HO}_{2} \leftrightarrow\right.$ $\mathrm{HOCH}_{2} \mathrm{O}+\mathrm{OH}$ ), and $\mathrm{HOCH}_{2} \mathrm{O}$ further decomposed to $\mathrm{HOCHO}$ and $\mathrm{H}$ (i.e., $\mathrm{HOCH}_{2} \mathrm{O} \leftrightarrow$ $\mathrm{HOCHO}+\mathrm{H}$ ). The latter was transformed to $\mathrm{HCO}, \mathrm{CO}$, and $\mathrm{CO}_{2}$ by consequent reactions. In other words, $\mathrm{H}$ abstraction formed $\mathrm{CH}_{2} \mathrm{OH}$ and $\mathrm{CH}_{3} \mathrm{O}$, which were confirmed to be the two main decomposition reactions of methanol.

Similar analyses were conducted to investigate the chemistry of ethanol at a stoichiometric composition, atmospheric pressure, and temperature of $310 \mathrm{~K}$ (Figure 3).

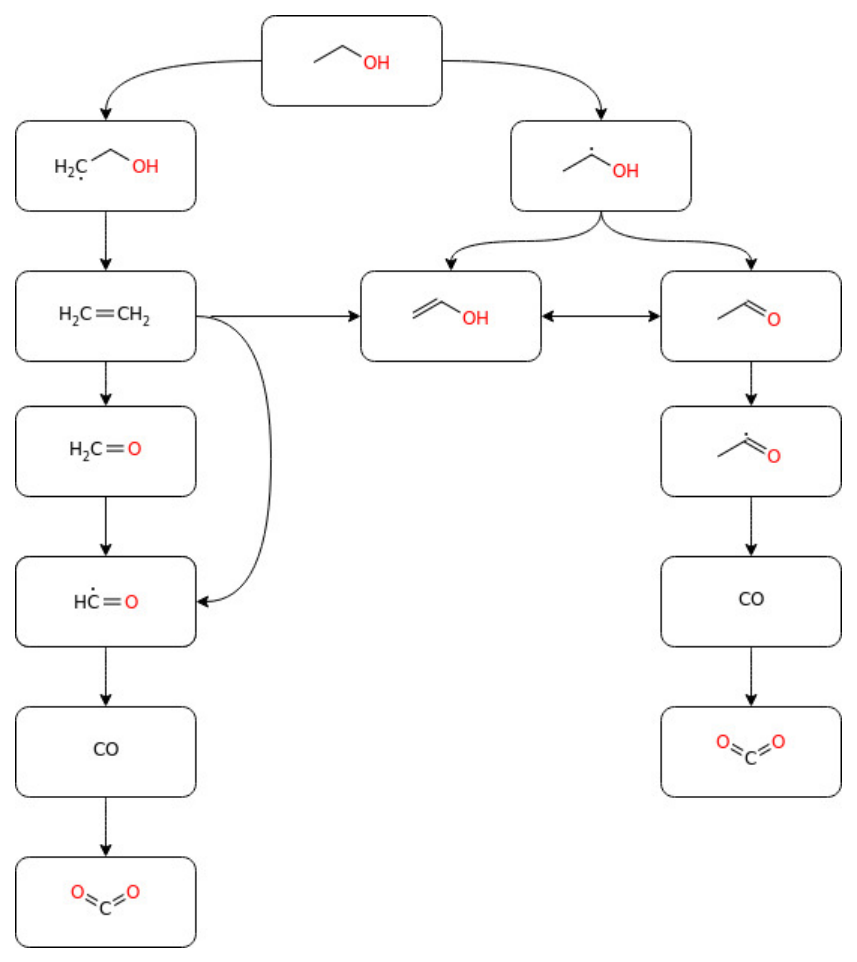

Figure 3. Simplified representation of the reaction paths of ethanol in air.

As can be seen from the figure, $\mathrm{sC}_{2} \mathrm{H}_{4} \mathrm{OH}(\mathrm{C}[\mathrm{CH}] \mathrm{O}$ in SMILES notation) was the main primary intermediate from ethanol decomposition through hydrogen abstraction by $\mathrm{HO}_{2}$. $\mathrm{sC}_{2} \mathrm{H}_{4} \mathrm{OH}$ further decomposed to $\mathrm{CH}_{3} \mathrm{CHO}$ and $\mathrm{C}_{2} \mathrm{H}_{3} \mathrm{OH}$ through $\mathrm{sC}_{2} \mathrm{H}_{4} \mathrm{OH} \leftrightarrow \mathrm{CH}_{3} \mathrm{CHO}$ $+\mathrm{H}$ and $\mathrm{sC}_{2} \mathrm{H}_{4} \mathrm{OH} \leftrightarrow \mathrm{C}_{2} \mathrm{H}_{3} \mathrm{OH}+\mathrm{H}$ reactions, respectively. The former was further decomposed to $\mathrm{CH}_{3} \mathrm{CO}$, which then decomposed to produce $\mathrm{CO}$ through $\mathrm{CH}_{3} \mathrm{CO}(+\mathrm{M}) \leftrightarrow$ $\mathrm{CH}_{3}+\mathrm{CO}+\mathrm{H}(+\mathrm{M})$. It is worthy to note that out of the five possible fuel decomposition reactions reported by Pichler and Nilsson (2020) [38] using a full mechanism, only one was retained in this reduced mechanism. The reduction from five fuel decomposition paths to one fuel decomposition path shows that under the target conditions, one reaction could fully describe the chemistry of ethanol combustion. Compared with the complex reaction mechanism used as a starting point, the reduced mechanism could significantly reduce the size of the mechanism and the computational cost. Moreover, $\mathrm{C}_{2} \mathrm{H}_{4}$, a soot precursor, was identified as one of the key intermediates from ethanol oxidation and considered in the RPA skeletal model of ethanol. Notably, this soot precursor could further react to generate $\mathrm{HCO}, \mathrm{C}_{2} \mathrm{H}_{3} \mathrm{OH}$, and $\mathrm{CH}_{3} \mathrm{CHO}$ intermediates through hydrogen abstraction by $\mathrm{OH}$ and $\mathrm{C}-\mathrm{C}$ bond cleavage by $\mathrm{O}$ with the following reactions: $\mathrm{C}_{2} \mathrm{H}_{4}+\mathrm{O} \leftrightarrow \mathrm{CH}_{3}+\mathrm{HCO}$, $\mathrm{C}_{2} \mathrm{H}_{4}+\mathrm{OH} \leftrightarrow \mathrm{CH}_{3} \mathrm{CHO}+\mathrm{H}$, and $\mathrm{C}_{2} \mathrm{H}_{4}+\mathrm{OH} \leftrightarrow \mathrm{C}_{2} \mathrm{H}_{3} \mathrm{OH}+\mathrm{H}$. In addition to this, $\mathrm{C}_{2} \mathrm{H}_{4}$ was also primarily responsible for the formation of other soot precursors, such as $\mathrm{C}_{2} \mathrm{H}_{3}$ and $\mathrm{C}_{2} \mathrm{H}_{2}$. Pichler and Nilsson (2020) reported the same decomposition reaction route for $\mathrm{C}_{2} \mathrm{H}_{4}$ [38]. Generally, it can be concluded from this study that the chance of soot formation 
from oxygenated biofuels is relatively low, because the dominant path $\left(\mathrm{CH}_{2} \mathrm{OH}\right.$ formation) did not lead to the production of soot precursors.

To further evaluate the RPA, sensitivity analysis was conducted to classify the reactions based on the absolute value of the obtained NSCs so that the normalized sensitivity coefficients could be compared to identify the reactions responsible for the formation and decomposition of the main intermediate and product species.

In Figure 4, the key reactions with their normalized sensitivity coefficient believed to affect the laminar burning velocity of methanol are shown. The sensitivity analysis was performed at different initial temperatures (310-1400K). From the study, it was observed that similar reactions were found to be sensitive to the flame speed under the studied reaction temperatures. Thus, for the sake of simplicity, the normalized sensitivity data of methanol at a temperature of $310 \mathrm{~K}$ are shown here. As can be seen from Figure 5, $\mathrm{HO}_{2}+\mathrm{OH} \leftrightarrow$ $\mathrm{H}_{2} \mathrm{O}+\mathrm{O}_{2}, \mathrm{HCO}(+\mathrm{M}) \leftrightarrow \mathrm{H}+\mathrm{CO}(+\mathrm{M}), \mathrm{H}+\mathrm{O}_{2}(+\mathrm{M}) \leftrightarrow \mathrm{HO}_{2}(+\mathrm{M}), \mathrm{HCO}+\mathrm{O}_{2} \leftrightarrow \mathrm{CO}+\mathrm{HO}_{2}$ and $\mathrm{H}+\mathrm{O}_{2} \leftrightarrow \mathrm{O}+\mathrm{OH}$ were the reactions significantly affecting the predicted laminar flame speed of methanol.

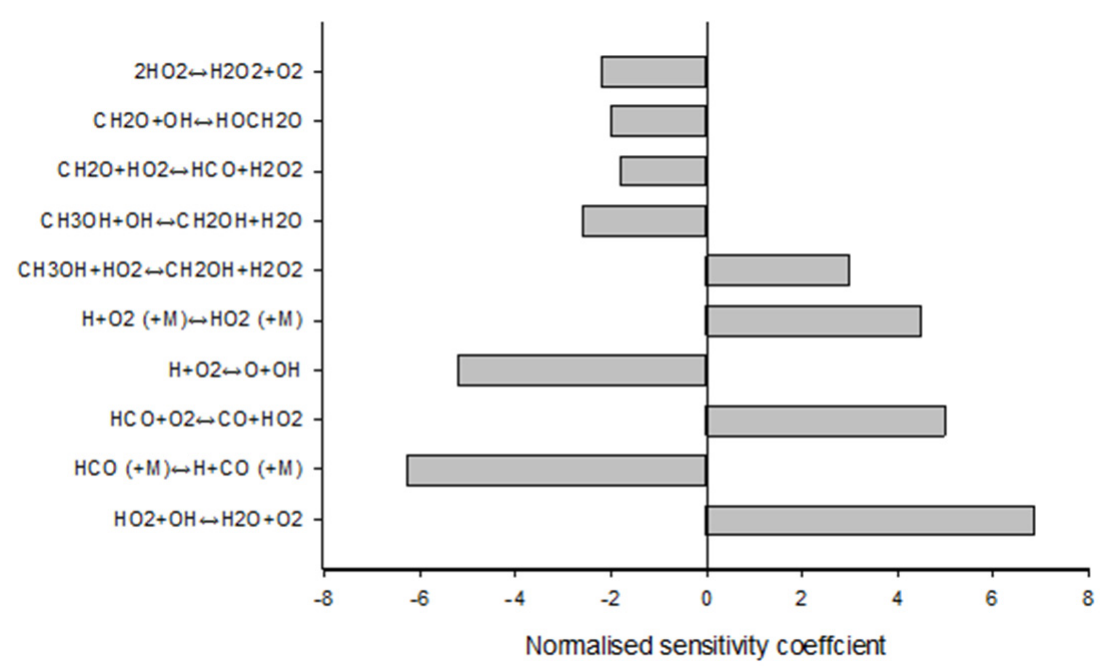

Figure 4. Sensitivity analysis for the laminar burning velocity of the stoichiometric methanol-air mixture at atmospheric pressure and the initial temperature (310 K).

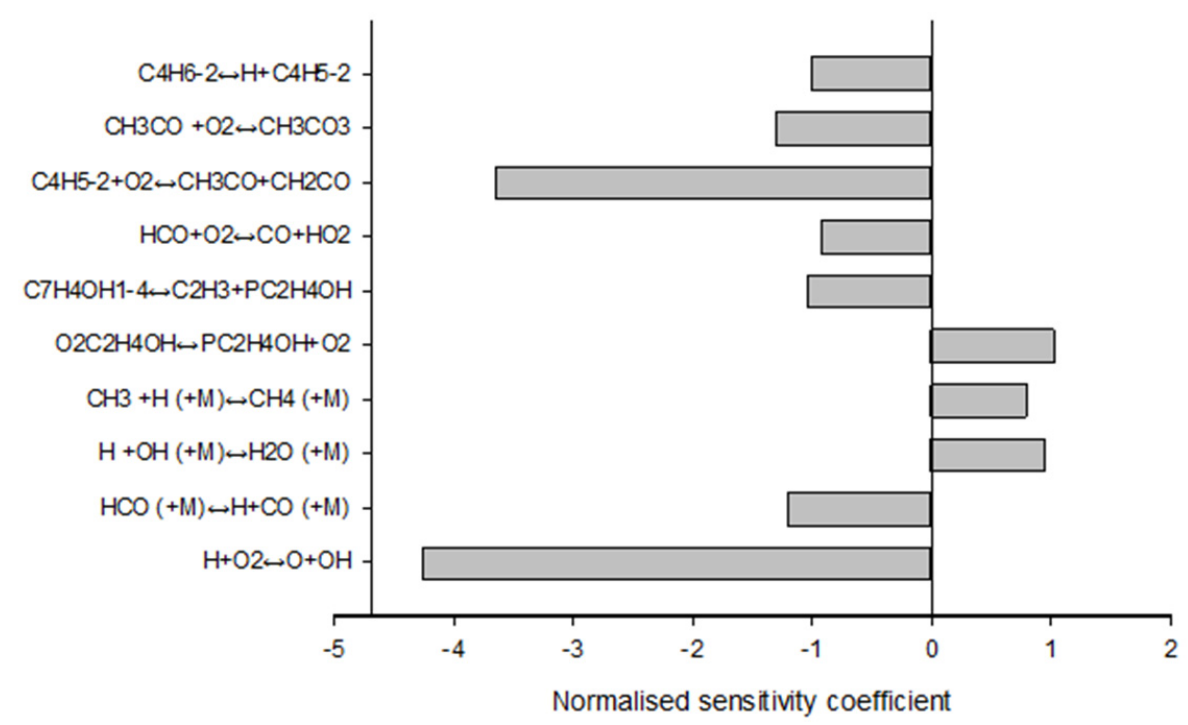

Figure 5. Sensitivity analysis for the laminar burning velocity of the stoichiometric ethanol-air mixture at atmospheric pressure and the initial temperature (310 K). 
Similarly, the normalized sensitivity coefficients of ethanol at various initial reaction temperatures (310-1400 K), atmospheric pressures, and stoichiometric compositions are shown in Figure 5. The key reactions responsible for the variation of the laminar flame speed of ethanol were identified at the specified conditions. As for the case of methanol, the reactions sensitive to the ethanol flame speed were observed to be quite similar at different initial temperatures (310-1400 K), and thus sensitive reactions at a temperature of $310 \mathrm{~K}$ have been shown here for illustration. As can be seen from the figure, $\mathrm{H}+\mathrm{O}_{2} \leftrightarrow$ $\mathrm{O}+\mathrm{OH}$ and $\mathrm{C}_{4} \mathrm{H}_{5}-2+\mathrm{O}_{2} \leftrightarrow \mathrm{CH}_{3} \mathrm{CO}+\mathrm{CH}_{2} \mathrm{CO}$ reactions were found to substantially affect the predicted laminar flame speed of ethanol. It is worth noting that in both methanol and ethanol, formyl radical decomposition $(\mathrm{HCO}(+\mathrm{M}) \leftrightarrow \mathrm{H}+\mathrm{CO}(+\mathrm{M}))$ and hydrogen atom abstraction by molecular oxygen $\left(\mathrm{HCO}+\mathrm{O}_{2} \leftrightarrow \mathrm{CO}+\mathrm{HO}_{2}\right)$ were primary sources of carbon monoxide under the studied conditions. The same result was reported by Metcalfe et al. (2013) [15] for hydrocarbon fuel combustion under flame conditions at high temperatures. From the combination of the information collected so far, the reduced mechanisms of methanol and ethanol containing 19 reactions and 20 reactions, respectively, with their rate coefficients are provided in Tables 2 and 3.

Table 2. Reduced mechanism for methanol as obtained in this work and implemented in CFD.

\begin{tabular}{|c|c|c|c|c|}
\hline No & Reaction & $\underset{\left(\mathrm{cm}^{3}, \mathrm{~mol}^{-1}, \mathrm{~s}^{-1}\right)}{\mathrm{A}}$ & $\mathrm{E}_{\mathrm{a}}\left(\mathrm{cal} \mathrm{mol} \mathrm{mo}^{-1}\right)$ & $\begin{array}{c}n \\
(-)\end{array}$ \\
\hline$\# 1$ & $\mathrm{HCO}+(\mathrm{M}) \leftrightarrow \mathrm{H}+\mathrm{CO}+(\mathrm{M})$ & $4.75 \times 10^{11}$ & $14,870.0$ & 0.66 \\
\hline \#2 & $\mathrm{HCO}+\mathrm{O}_{2} \leftrightarrow \mathrm{CO}+\mathrm{HO}_{2}$ & $7.58 \times 10^{12}$ & 410.0 & 0.00 \\
\hline \#3 & $\mathrm{CO}+\mathrm{OH} \leftrightarrow \mathrm{CO}_{2}+\mathrm{H}^{* *}$ & $6.34 \times 10^{4}$ & -355.7 & 2.05 \\
\hline$\# 4$ & $\mathrm{CO}+\mathrm{OH} \leftrightarrow \mathrm{CO}_{2}+\mathrm{H}^{* *}$ & $5.76 \times 10^{12}$ & 331.8 & -0.66 \\
\hline \#5 & $\mathrm{HOCH}_{2} \mathrm{O} \leftrightarrow \mathrm{HOCHO}+\mathrm{H}$ & $1.00 \times 10^{14}$ & $14,900.0$ & 0.00 \\
\hline \#6 & $\mathrm{HOCHO}+\mathrm{CH}_{3} \rightarrow \mathrm{CH}_{4}+\mathrm{CO}+\mathrm{OH}$ & $3.90 \times 10^{-7}$ & 2200.0 & 5.80 \\
\hline \multirow{2}{*}{$\# 7$} & \multirow{2}{*}{$\mathrm{CH}_{3} \mathrm{O}(+\mathrm{M}) \leftrightarrow \mathrm{CH}_{2} \mathrm{O}+\mathrm{H}(+\mathrm{M}) * * *$} & $6.80 \times 10^{13}$ & $26,170.0$ & 0.00 \\
\hline & & $1.87 \times 10^{25}$ & $24,307.0$ & -3.00 \\
\hline \#8 & $\mathrm{CH}_{2} \mathrm{OH}+\mathrm{O}_{2} \leftrightarrow \mathrm{CH}_{2} \mathrm{O}+\mathrm{HO}_{2} * *$ & $1.51 \times 10^{15}$ & 0.0 & -1.00 \\
\hline$\# 9$ & $\mathrm{CH}_{2} \mathrm{OH}+\mathrm{O}_{2} \leftrightarrow \mathrm{CH}_{2} \mathrm{O}+\mathrm{HO}_{2} * *$ & $2.41 \times 10^{14}$ & 5017.0 & 0.0 \\
\hline$\# 10$ & $\mathrm{CH}_{2} \mathrm{O}+\mathrm{OH} \leftrightarrow \mathrm{HOCH}_{2} \mathrm{O}$ & $4.50 \times 10^{15}$ & 0.0 & -1.10 \\
\hline \#11 & $\mathrm{CH}_{3} \mathrm{OH}+\mathrm{OH} \leftrightarrow \mathrm{CH}_{2} \mathrm{OH}+\mathrm{H}_{2} \mathrm{O}$ & $3.08 \times 10^{4}$ & -806.7 & 2.60 \\
\hline \#12 & $\mathrm{CH}_{2} \mathrm{OH}+\mathrm{HO}_{2} \leftrightarrow \mathrm{HOCH}_{2} \mathrm{O}+\mathrm{OH}$ & $1.00 \times 10^{13}$ & 0.0 & 0.00 \\
\hline \#13 & $\mathrm{CH}_{3} \mathrm{OH}+\mathrm{HCO} \leftrightarrow \mathrm{CH}_{2} \mathrm{OH}+\mathrm{CH}_{2} \mathrm{O}$ & $9.63 \times 10^{3}$ & $13,110.0$ & 2.90 \\
\hline \#14 & $\mathrm{CH}_{3} \mathrm{OH}+\mathrm{O}_{2} \leftrightarrow \mathrm{CH}_{2} \mathrm{OH}+\mathrm{HO}_{2}$ & $2.05 \times 10^{13}$ & $44,900.0$ & 0.00 \\
\hline \#15 & $\mathrm{CH}_{2} \mathrm{O}+\mathrm{OH} \leftrightarrow \mathrm{HCO}+\mathrm{H}_{2} \mathrm{O}$ & $7.82 \times 10^{7}$ & -1055.0 & 1.63 \\
\hline \#16 & $\mathrm{CH}_{2} \mathrm{O}+\mathrm{H} \leftrightarrow \mathrm{HCO}+\mathrm{H}_{2}$ & $5.74 \times 10^{7}$ & 2740.0 & 1.90 \\
\hline \#17 & $\mathrm{CH}_{3} \mathrm{OH}+\mathrm{O} \leftrightarrow \mathrm{CH}_{2} \mathrm{OH}+\mathrm{OH}$ & $3.88 \times 10^{5}$ & 3080.0 & 2.50 \\
\hline \#18 & $\mathrm{CH}_{3} \mathrm{OH}+\mathrm{H} \leftrightarrow \mathrm{CH}_{3} \mathrm{O}+\mathrm{H}_{2}$ & $1.99 \times 10^{5}$ & $10,300.0$ & 2.56 \\
\hline \#19 & $\mathrm{CH}_{3} \mathrm{OH}+\mathrm{OH} \leftrightarrow \mathrm{CH}_{3} \mathrm{O}+\mathrm{H}_{2} \mathrm{O}$ & $1.50 \times 10^{2}$ & -763.0 & 3.03 \\
\hline
\end{tabular}

* Please note that units must be adapted in compliance with the reaction order, assumed as elementary. ** Reactions are included as duplicates in the adopted mechanism. ${ }^{* * *}$ Falloff reaction, where the first set of coefficients refers to $\mathrm{K}_{\mathrm{f}}$, whereas the second refers to $\mathrm{K}_{\mathrm{f} 0}$.

For the sake of evaluating the resulting skeletal model, the laminar burning velocity predicted by the initial version of the mechanism published by Sarathy et al. [30] (detailed mechanism) and the version obtained in this work (reduced mechanism) were compared with the experimental data reported in the literature $[36,37]$. To limit the effects of systematic errors, the results from different experimental apparatus were considered at this stage. The average values and intervals, including all the cited data for stoichiometric compositions, are reported in Table 4 together with the numerical estimations. 
Table 3. Reduced mechanism for ethanol as obtained in this work and implemented in CFD.

\begin{tabular}{|c|c|c|c|c|}
\hline No & Reaction & $\underset{\left(\mathrm{cm}^{3}, \mathrm{~mol}^{-1}, \mathrm{~s}^{-1}\right)}{\text { * }}$ & $\mathrm{E}_{\mathrm{a}}\left(\mathrm{cal} \mathrm{mol}^{-1}\right)$ & $\begin{array}{c}n \\
(-)\end{array}$ \\
\hline$\# 1$ & $\mathrm{HCO}+(\mathrm{M}) \leftrightarrow \mathrm{H}+\mathrm{CO}(+\mathrm{M})$ & $4.75 \times 10^{11}$ & $14,870.0$ & 0.66 \\
\hline$\# 2$ & $\mathrm{CO}+\mathrm{OH} \leftrightarrow \mathrm{CO}_{2}+\mathrm{H}^{* *}$ & $6.34 \times 10^{4}$ & -355.7 & 2.05 \\
\hline \#3 & $\mathrm{CO}+\mathrm{OH} \leftrightarrow \mathrm{CO}_{2}+\mathrm{H}^{* *}$ & $5.76 \times 10^{12}$ & 331.8 & -0.66 \\
\hline$\# 4$ & $\mathrm{CH}_{3}+\mathrm{O} \leftrightarrow \mathrm{CH}_{2} \mathrm{O}+\mathrm{H}$ & $5.54 \times 10^{13}$ & -136.0 & 0.05 \\
\hline$\# 5$ & $\mathrm{CH}_{2}+\mathrm{O}_{2} \leftrightarrow \mathrm{CH}_{2} \mathrm{O}+\mathrm{O}$ & $1.26 \times 10^{6}$ & 1604.0 & 2.42 \\
\hline$\# 6$ & $\mathrm{CH}_{2} \mathrm{O}+\mathrm{OH} \leftrightarrow \mathrm{HCO}+\mathrm{H}_{2} \mathrm{O}$ & $7.82 \times 10^{7}$ & -1055.0 & 1.63 \\
\hline$\# 7$ & $\mathrm{CH}_{2} \mathrm{O}+\mathrm{H} \leftrightarrow \mathrm{HCO}+\mathrm{H}_{2}$ & $5.74 \times 10^{7}$ & 2740.0 & 1.90 \\
\hline$\# 8$ & $\mathrm{C}_{2} \mathrm{H}_{4}+\mathrm{OH} \leftrightarrow \mathrm{C}_{2} \mathrm{H}_{3} \mathrm{OH}+\mathrm{H}^{* * * *}$ & $3.19 \times 10^{5}$ & 5255.6 & 2.19 \\
\hline \#9 & $\mathrm{C}_{2} \mathrm{H}_{4}+\mathrm{OH} \leftrightarrow \mathrm{pC}_{2} \mathrm{H}_{4} \mathrm{OH}{ }^{* * * *}$ & $2.56 \times 10^{36}$ & 6946.1 & -7.75 \\
\hline \#10 & $\mathrm{CH}_{3} \mathrm{CHO}+\mathrm{H} \leftrightarrow \mathrm{CH}_{3} \mathrm{CO}+\mathrm{H}_{2}$ & $1.31 \times 10^{5}$ & 1220.0 & 2.58 \\
\hline \#11 & $\mathrm{CH}_{3} \mathrm{CHO}+\mathrm{OH} \leftrightarrow \mathrm{CH}_{3} \mathrm{CO}+\mathrm{H}_{2} \mathrm{O}$ & $3.37 \times 10^{12}$ & -619.0 & 0.00 \\
\hline$\# 12$ & $\mathrm{C}_{2} \mathrm{H}_{5} \mathrm{OH}+\mathrm{O} \leftrightarrow \mathrm{sC}_{2} \mathrm{H}_{4} \mathrm{OH}+\mathrm{OH}$ & $1.45 \times 10^{5}$ & 876.0 & 2.47 \\
\hline \#13 & $\mathrm{C}_{2} \mathrm{H}_{3} \mathrm{OH}+\mathrm{H} \leftrightarrow \mathrm{pC}_{2} \mathrm{H}_{4} \mathrm{OH}$ & $3.01 \times 10^{8}$ & 3670.0 & 1.58 \\
\hline \#14 & $\mathrm{C}_{2} \mathrm{H}_{5} \mathrm{OH}+\mathrm{C}_{2} \mathrm{H}_{5} \leftrightarrow \mathrm{sC}_{2} \mathrm{H}_{4} \mathrm{OH}+\mathrm{C}_{2} \mathrm{H}_{6}$ & $5.00 \times 10^{10}$ & $10,400.0$ & 0.00 \\
\hline \#15 & $\mathrm{CH}_{3} \mathrm{CO}(+\mathrm{M}) \leftrightarrow \mathrm{CH}_{3}+\mathrm{CO}(+\mathrm{M})^{* * *}$ & $\begin{array}{l}1.07 \times 10^{12} \\
5.65 \times 10^{18}\end{array}$ & $\begin{array}{l}16,900.0 \\
14,600.0\end{array}$ & $\begin{array}{c}0.60 \\
-0.97\end{array}$ \\
\hline \#16 & $\mathrm{CH}_{3} \mathrm{CHO}+\mathrm{HO}_{2} \leftrightarrow \mathrm{CH}_{3} \mathrm{CO}+\mathrm{H}_{2} \mathrm{O}_{2}$ & $3.01 \times 10^{12}$ & $11,920.0$ & 0.00 \\
\hline$\# 17$ & $\mathrm{sC}_{2} \mathrm{H}_{4} \mathrm{OH}+\mathrm{O}_{2} \leftrightarrow \mathrm{CH}_{3} \mathrm{CHO}+\mathrm{HO}_{2}^{* * * *}$ & $5.28 \times 10^{17}$ & 839.0 & -1.60 \\
\hline \#18 & $\mathrm{CH}_{3} \mathrm{CHO}+\mathrm{O}_{2} \leftrightarrow \mathrm{CH}_{3} \mathrm{CO}+\mathrm{HO}_{2}$ & $3.01 \times 10^{13}$ & $39,150.0$ & 0.00 \\
\hline \#19 & $\mathrm{sC}_{2} \mathrm{H}_{4} \mathrm{OH} \leftrightarrow \mathrm{CH}_{3} \mathrm{CHO}+\mathrm{H}^{* * * *}$ & $5.36 \times 10^{55}$ & $51,886.0$ & -13.20 \\
\hline \#20 & $\mathrm{C}_{2} \mathrm{H}_{5} \mathrm{OH}+\mathrm{HO}_{2} \leftrightarrow \mathrm{sC}_{2} \mathrm{H}_{4} \mathrm{OH}+\mathrm{H}_{2} \mathrm{O}_{2}$ & $2.80 \times 10^{-2}$ & 8530.0 & 4.30 \\
\hline
\end{tabular}

* Please note that units must be adapted in compliance with the reaction order, assumed as elementary. ${ }^{* *}$ Reactions are included as duplicates in the adopted mechanism. ${ }^{* * *}$ Falloff reaction, where the first set of coefficients refers to $\mathrm{K}_{\mathrm{f}}$, whereas the second refers to $\mathrm{K}_{\mathrm{f} 0} \cdot{ }^{* * * *}$ Pressure dependent reaction, with reported coefficients to refer to the atmospheric pressure.

Table 4. Comparison of simulation and experimental results for the laminar burning velocity of methanol and ethanol under stoichiometric conditions and atmospheric pressure [36,37]. In brackets, the relative deviations from the experimental data are defined as 100* (estimated value - measured value)/measured value.

\begin{tabular}{cccc}
\hline \multirow{2}{*}{ Fuel } & \multirow{2}{*}{ Experiment $(\mathbf{c m} / \mathbf{s})$} & \multicolumn{2}{c}{ Estimation $(\mathbf{c m} / \mathbf{s})$} \\
\cline { 3 - 4 } & & Detailed Mechanism & Reduced Mechanism \\
\hline Methanol & $40 \pm 5$ & $40.0(0.0)$ & $37.0(-7.5)$ \\
Ethanol & $44 \pm 4$ & $46.1(4.8)$ & $41.5(-5.7)$ \\
\hline
\end{tabular}

The reported accuracy of the reduced mechanism allowed for its implementation in CFD models. Thus, to better understand the pool fire behavior of oxygenated biofuels, the numerical study of methanol and ethanol with the help of single-step chemistry and a reduced mechanism were evaluated against the experimental results reported in the literature [36,37]. To this aim, the burning rate, radiative heat flux, and heat release rate were considered under atmospheric conditions, and the results are shown in Table 5. Furthermore, the maximum temperature $\left(\mathrm{T}_{\max }\right)$ within the flame zone was reported as per the evaluation of the combustion efficiency.

It can be seen from Table 5 that the simulated values with the two mechanisms fairly predicted the burning rate and agreed with the experimental data reported under the same conditions. However, regardless of the implemented approach, the numerical estimations slightly overestimated the average value of the radiative heat flux emitted from the pool fire for methanol and underestimated this parameter in the case of ethanol. The maximum flame temperature data could be used to explain the opposite direction of the discussed trend. Indeed, the single-step chemistry considerably overpredicted $\mathrm{T}_{\max }$ for either methanol or ethanol, whereas the reduced mechanism provided more accurate estimations. In this view, it is worth noting that the heat release rate was inferred by the 
measured burning rate for the experimental case, assuming ideal combustion. Hence, it should be intended as an upper bound for numerical simulations estimating that parameter directly. In this perspective, it is possible to conclude that the higher heat release rates observed for the single-step chemistry case were related to the assumption of complete oxidation exclusively, which is unrealistic for uncontrolled and diffusive flames. On the other hand, the reduced mechanism made possible the accurate estimation of the real product distribution, providing more reliable values. In addition, since these tests reported pool fires, they locally involved a wide range of temperatures and compositions. Thus, the capacity of the reduced mechanism to mimic these experimental data suggests its validity for the characterization of accidental release of the investigated species. Hence, the integration of a reduced mechanism in the CFD model removes a conservative assumption for consequence analyses, making numerical estimations closer to the real systems. Comparably, the reduced mechanism seemed to show deviations in the case of ethanol rather than methanol, which might be attributed to the rate coefficients for $\mathrm{CH}_{3} \mathrm{CO}(+\mathrm{M})$ $\leftrightarrow \mathrm{CH}_{3}+\mathrm{CO}(+\mathrm{M})$. Indeed, the kinetic parameters included in the detailed mechanism were fitted from the experimental data in which the whole temperature range considered in the present study was not contained. In addition, there is no clear information regarding the source of rate coefficients for certain sensitive reactions (e.g., $\mathrm{CH}_{2}+\mathrm{O}_{2} \leftrightarrow \mathrm{CH}_{2} \mathrm{O}+\mathrm{O}$ ), and it is expected that the deviation may be related to the rate coefficients corresponding to this reaction as well. In general, from the present study, we can conclude that, despite some discrepancies, the reduced mechanism was in fair agreement with the experimental and single-step chemistry kinetic model already included in FDS, providing a more comprehensive feature for detailed analyses.

Table 5. Summary of parameters obtained from the present study for 1-m diameter methanol [35] and ethanol [36] pool fires. In brackets, the relative deviations from the experimental data are defined as $100^{*}$ (estimated value - measured value)/measured.

\begin{tabular}{cccc}
\hline Parameters & Experimental & Single-Step Chemistry & Reduced Mechanism \\
\hline \multicolumn{3}{c}{ Methanol } \\
\hline Heat flux $\left(\mathrm{kW} / \mathrm{m}^{2}\right)$ & $5.1 \pm 1.0$ & $8.2(60.8)$ & $6.7(31.4)$ \\
Burning rate $(\mathrm{kg} / \mathrm{s})$ & $0.013 \pm 0.009$ & $0.013(0.0)$ & $0.011(-15.4)$ \\
Heat release rate $(\mathrm{kW})$ & $256 \pm 19$ & $272(6.3)$ & $261(1.9)$ \\
$\mathrm{T}_{\max }(\mathrm{K})$ & 1370 & $1662(21.3)$ & $977(-28.7)$ \\
\hline & & Ethanol & $14.8(-26.0)$ \\
\hline Heat flux $\left(\mathrm{kW} / \mathrm{m}^{2}\right)$ & 20.0 & $17.2(-14.0)$ & $0.019(-17.4)$ \\
Burning rate $\left(\mathrm{kg} / \mathrm{m}^{2} / \mathrm{s}\right)$ & 0.023 & $0.026(13.0)$ & $1288(36.4)$ \\
$\mathrm{T}_{\max }(\mathrm{K})$ & 944 & $1709(81.0)$ &
\end{tabular}

\section{Conclusions}

In this work, the most important reactions and pathways for the combustion of small-scale methanol and ethanol fires were identified. To this aim, a detailed kinetic mechanism was reduced to a skeletal model suitable for implementation in CFD codes. The estimation quality of the resulting mechanisms was tested in terms of the laminar burning velocity, burning rate, flame temperature, and produced heat flux. The predicted values were compared either with numerical estimations derived from the single-step reaction approach or the experimental data from the literature. The observed accuracy validates the approach and the produced mechanisms, making them suitable to mimic the combustion behavior of light alcohols in real systems. In contrast to single-step chemistry, the reduced mechanism produced in this work was able to effectively include product distribution, thereby providing a tool for comprehensive characterization of the investigated scenario. 
Author Contributions: Conceptualization, F.M.W. and G.P.; methodology, F.M.W. and G.P.; software, F.M.W.; formal analysis, F.M.W. and G.P.; investigation, F.M.W., G.P. and E.S.; resources, E.S.; data curation, F.M.W. and G.P.; writing-original draft preparation, F.M.W.; writing-review and editing, G.P. and E.S.; visualization, F.M.W. and G.P.; supervision, G.P. and E.S. All authors have read and agreed to the published version of the manuscript.

Funding: This research received no external funding.

Conflicts of Interest: The authors declare no conflict of interest.

\section{References}

1. Sedano, C.A.; López, O.D.; Ladino, A.; Munoz, F. Prediction of a Small-Scale Pool Fire with FireFoam. Int. J. Chem. Eng. 2017, 2017, 1-12. [CrossRef]

2. Algayyim, S.J.M.; Wandel, A.P.; Yusaf, T.; Hamawand, I. Production and application of ABE as a biofuel. Renew. Sustain. Energy Rev. 2018, 82, 1195-1214. [CrossRef]

3. He, X. A novel hybrid digestion-gasification process integrated with membranes for efficient conversion of biomass to bio-alcohols. Green Energy Environ. 2021, 6, 15-21. [CrossRef]

4. Yang, K.; Gu, Z.; Long, Y.; Lin, S.; Lu, C.; Zhu, X.; Wang, H.; Li, K. Hydrogen production via chemical looping reforming of coke oven gas. Green Energy Environ. 2021, 6, 678-692. [CrossRef]

5. Salzano, E.; di Serio, M.; Santacesaria, E. Emerging Safety Issues for Biodiesel Production Plant. Chem. Eng. Trans. 2010, 19, 415-420.

6. Moss, P. Biodiesel plant safety. Biodiesel Mag. 2010, 2010. Available online: http://www.biodieselmagazine.com/articles/4055 /biodiesel-plant-safety/ (accessed on 1 November 2021).

7. Kwon, O.; Faeth, G. Flame/stretch interactions of premixed hydrogen-fueled flames: Measurements and predictions. Combust. Flame 2001, 124, 590-610. [CrossRef]

8. Herbinet, O.; Pitz, W.J.; Westbrook, K.C. Detailed chemical kinetic mechanism for the oxidation of biodiesel fuels blend surrogate. Combust. Flame 2010, 157, 893-908. [CrossRef]

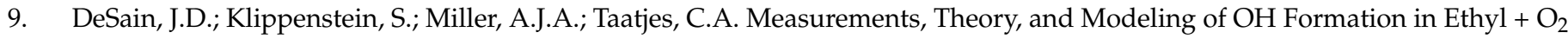
and Propyl $+\mathrm{O}_{2}$ Reactions. J. Phys. Chem. A 2003, 107, 4415-4427. [CrossRef]

10. Zhang, P.; Ji, W.; He, T.; He, X.; Wang, Z.; Yang, B.; Law, C.K. First-stage ignition delay in the negative temperature coefficient behavior: Experiment and simulation. Combust. Flame 2016, 167, 14-23. [CrossRef]

11. Curran, H.; Gaffuri, P.; Pitz, W.; Westbrook, C. A Comprehensive Modeling Study of n-Heptane Oxidation. Combust. Flame 1998, 114, 149-177. [CrossRef]

12. Battin-Leclerc, F. Detailed chemical kinetic models for the low-temperature combustion of hydrocarbons with application to gasoline and diesel fuel surrogates. Prog. Energy Combust. Sci. 2008, 34, 440-498. [CrossRef]

13. Curran, H.J. Developing detailed chemical kinetic mechanisms for fuel combustion. Proc. Combust. Inst. 2019, 37, 57-81. [CrossRef]

14. Dooley, S.; Burke, M.; Chaos, M.; Stein, Y.; Dryer, F.L.; Zhukov, V.P.; Finch, O.; Simmie, J.; Curran, H. Methyl formate oxidation: Speciation data, laminar burning velocities, ignition delay times, and a validated chemical kinetic model. Int. J. Chem. Kinet. 2010, 42, 527-549. [CrossRef]

15. Metcalfe, W.K.; Burke, S.M.; Ahmed, S.S.; Curran, H.J. A Hierarchical and Comparative Kinetic Modeling Study of C1 - C2 Hydrocarbon and Oxygenated Fuels. Int. J. Chem. Kinet. 2013, 45, 638-675. [CrossRef]

16. Wang, H.; Sheen, D. Combustion kinetic model uncertainty quantification, propagation and minimization. Prog. Energy Combust. Sci. 2015, 47, 1-31. [CrossRef]

17. Wu, H.; Rota, R.; Morbidelli, M.; Varma, A. Parametric sensitivity in fixed-bed catalytic reactors with reverse-flow operation. Chem. Eng. Sci. 1999, 54, 4579-4588. [CrossRef]

18. Battin-Leclerc, F.; Simmie, J.M.; Blurock, E. Cleaner combustion. Developing Detailed Chemical Kinetic Models. Series: Green Energy and Technology; Springer: Cham, Switzerland, 2013.

19. Lu, T.; Law, C.K. Toward accommodating realistic fuel chemistry in large-scale computations. Prog. Energy Combust. Sci. 2009, 35, 192-215. [CrossRef]

20. Pio, G.; Carboni, M.; Salzano, E. Realistic aviation fuel chemistry in computational fluid dynamics. Fuel 2019, $254,115676$. [CrossRef]

21. Weckman, E.; Strong, A. Experimental investigation of the turbulence structure of medium-scale methanol pool fires. Fire Saf. J. 1996, 27, 87-88. [CrossRef]

22. Falkenstein-Smith, R.; Sung, K.; Chen, J.; Hamins, A. Chemical structure of medium-scale liquid pool fires. Fire Saf. J. 2021, 120, 103099. [CrossRef]

23. Vali, A.; Nobes, D.S.; Kostiuk, L.W. Effects of altering the liquid phase boundary conditions of methanol pool fires. Exp. Therm. Fluid Sci. 2013, 44, 786-791. [CrossRef]

24. Fischer, S.J.; Hardouin-Duparc, B.; Grosshandler, W.L. The structure and radiation of an ethanol pool fire. Combust. Flame 1987, 70, 291-306. [CrossRef] 
25. McGrattan, K.; Hostikka, S.; McDermott, R.; Floyd, J.; Weinschenk, C.; Overholt, K. Fire Dynamics Simulator User's Guide; NIST: Gaithersburg, MD, USA, 2013; Volume 1019, pp. 1-339.

26. Wen, J.; Kang, K.; Donchev, T.; Karwatzki, J. Validation of FDS for the prediction of medium-scale pool fires. Fire Saf. J. 2007, 42, 127-138. [CrossRef]

27. Prasad, K.; Li, C.; Kailasanath, K.; Ndubizu, C.; Ananth, R.; Tatem, P.A. Numerical modelling of methanol liquid pool fires Combust. Theory Model. 1999, 3, 743-768. [CrossRef]

28. Kee, R.; Rupley, F.M.; Miller, J.A.; Coltrin, M.E.; Grcar, J.F.; Meeks, E.; Moffat, H.K.; Lutz, A.E.; Dixon-Lewis, G.; Smooke, M.D.; et al. AURORA Application User Manual-CHEMKIN Collection; Reaction Design, Inc.: San Diego, CA, USA, 2003.

29. Sarathy, S.M.; Vranckx, S.; Yasunaga, K.; Mehl, M.; Osswald, P.; Metcalfe, W.K.; Westbrook, C.K.; Pitz, W.J.; Kohse-Höinghaus, K.; Fernandes, R.X.; et al. A comprehensive chemical kinetic combustion model for the four butanol isomers. Combust. Flame 2012, 159, 2028-2055. [CrossRef]

30. Rau, F.; Sandra Hartl, S.; Voss, M.; Still, C.H.; Trimis, D. The Laminar Burning Velocity of Iso-Octane, Ethanol and Iso-Butanol using the Heat Flux Burner and the Closed Combustion Vessel. Fuel 2015, 140, 10-16. [CrossRef]

31. Pio, G.; Barba, D.; Palma, V.; Salzano, E. A Numerical Study on the Effect of Temperature and Composition on the Flammability of Methane-Hydrogen Sulfide Mixtures. Combust. Sci. Technol. 2019, 191, 1541-1557. [CrossRef]

32. Goodwin, D. An open-source, extensible software suite for CVD process simulation. Chem. Vap. Depos. XVI EUROCVD 2003, 14, 2003-2008.

33. Pio, G.; Palma, V.; Salzano, E. Comparison and Validation of Detailed Kinetic Models for the Oxidation of Light Alkenes. Ind. Eng. Chem. Res. 2018, 57, 7130-7135. [CrossRef]

34. Damodara, V.; Chen, D.H.; Lou, H.H.; Rasel, K.M.; Richmond, P.; Wang, A.; Li, X. Reduced combustion mechanism for C1-C4 hydrocarbons and its application in computational fluid dynamics flare modeling. J. Air Waste Manag. Assoc. 2017, 67, 599-612. [CrossRef] [PubMed]

35. Rengel, B.; Mata, C.; Pastor, E.; Casal, J.; Planas, E. A priori validation of CFD modelling of hydrocarbon pool fires. J. Loss Prev. Process. Ind. 2018, 56, 18-31. [CrossRef]

36. Sung, K.; Chen, J.; Bundy, M.; Hamins, A. The characteristics of a 1 m methanol pool fire. Fire Saf. J. 2021, 120, 103121. [CrossRef]

37. Sharma, A.; Vishwakarma, P.K.; Mishra, S.; Mishra, K.B. Visible length and thermal radiation of WCO biodiesel and ethanol pool fires. Fuel 2020, 280, 118396. [CrossRef]

38. Pichler, C.; Nilsson, E. Pathway analysis of skeletal kinetic mechanisms for small alcohol fuels at engine conditions. Fuel 2020, 275, 117956. [CrossRef] 